\title{
INFLUENCE THE NON-METALLIC INCLUSIONS ON BENDING FATIGUE STRENGTH OF MEDIUM-CARBON STRUCTURAL STEEL MELTED IN AN ELECTRIC FURNACE
}

\author{
${ }^{1}$ Tomasz LIPIŃSKI, ${ }^{2}$ Anna WACH, ${ }^{3}$ Dariusz KARPISZ \\ 1 University of Warmia and Mazury in Olsztyn, Poland EU, tomaszlipinski.t1@gmail.com \\ 2University of Warmia and Mazury in Olsztyn, Poland EU, anna.wach@uwm.edu.pl \\ ${ }^{3}$ Cracow University of Technology, Poland, EU, dariusz.karpisz@pk.edu.pl
}

https://doi.org/10.37904/metal.2020.3459

\begin{abstract}
Non-metallic inclusions are one of the factors that influence the fatigue strength of steel. Although steel has a relatively small number of non-metallic inclusions, those impurities have a considerable impact on the material's technological and strength parameters, in particular fatigue strength and life. The study was performed on 7 heats produced in an industrial plant. Fourteen heats were produced in 140 ton electric furnaces. The experimental variants were compared in view of the applied melting technology and heat treatment options. The results were presented to account for the correlations between the fatigue strength coefficient during rotary bending, the diameter of and spacing between submicroscopic impurities. Equations for calculating the fatigue strength coefficient at each tempering temperature and a general equation for all tempering temperatures were proposed. Equations for estimating the fatigue strength coefficient based on the relative volume of submicroscopic non-metallic inclusions were also presented. The relationship between the fatigue strength and hardness of high-grade steel vs. the quotient of the diameter of impurities and the spacing between impurities were determined. The analyzed material was one grade of medium-carbon structural steel. The proposed linear regression equations supported the determination of fatigue strength coefficient and bending fatigue strength as a function of hardness taking into account impurities. The proposed equations contributes to the existing knowledge base of practices impact of impurities with various diameters and spacing between non-metalic inclusion on fatigue strength.
\end{abstract}

Keywords: Steel, impurities, non-metalic inclusions, fatigue strength, bending fatigue strength

\section{INTRODUCTION}

The properties of medium carbon steel are influence of different factors, including chemical composition, manufacturing technology, working conditions and other. The most harmful in processes of exploitation are random and unforeseeable damages and breakdowns of machines. The reasons of breakdown may depend from human factor, from constructional or material factor ant other. The most important are the called out with fatigue of material crack are the cause of unexpected appearing damages. There are many of factors influencing on fatigue strength of materials. The tensions of, cycle, of frequency influence, size and the shape of object of, temperature, corrosion, environment, thermal processing, state of surface as well as the structural defects we can include to main factors. One of the most important material factors responsible for sudden damage is the unfavorable steel microstructure. In addition to the typical components of the microstructure resulting from the planned chemical composition and heat treatment of steel are non-metalic inclusions $[1,2]$. The quantity and quality of non-metallic inclusions is determined mostly by the steel melting technology. Outfurnace treatment regimes are also introduced to minimize the quantity of non-metallic inclusions. The impurity content is also a key determinant of the quality of high-grade steel. Inclusions may also play an important role, subject to their type and shape. Yet as regards steel, non-metallic inclusions have mostly a 
negative effect which is dependent on their content, size, shape and distribution [3-5]. Currently exists many hypotheses of influence individual factors on fatigue strength. The hypotheses of accumulation of fatigue strength are worked out. There are put in of safety coefficients making up the unforesighting of events or hatches in knowledge [6].

The influence of impurities on fatigue strength has been researched extensively, but very few studies analyze the effect of impurities on the coefficient who is the quotient of fatigue strength $\mathrm{zg}$ divided by Vickers hardness $\mathrm{HV}$, which is used to estimate fatigue strength based on hardness, i.e. in non-destructive tests. In this study, attempts were made to analyze the impact of impurities with various diameters and spacing between nonmetalic inclusion $\alpha$ on fatigue strength coefficient $k$ determined under rotary bending fatigue strength zgo of high purity steels produced in an industrial plant.

Such investigation may be interested for production of tools [7,8] and wires [9]. The gathered dataset appears to be also inspiring to data analyses i.e. a morphology testing $[10,11]$, an image analysis of a surface layer [12-14], an analysis of experiments [15,16], a decision support [17] and uncertainty analysis [18].

\section{MATERIALS AND METHODS}

Steel was melted in a 140-ton basic arc furnace. The study was performed on 7 heats produced in an industrial plant. The metal was tapped into a ladle, it was desulfurized and 7-ton ingots were uphill teemed. Steel was additionally refined with argon after tapping into a ladle. Steel was poured into moulds. Billets with a square section of $100 \times 100 \mathrm{~mm}$ were rolled with the use of conventional methods. Billet samples were collected to determine: chemical composition - the content of alloy constituents was estimated with the use of LECO analyzers an AFL FICA 31000 quantometer and conventional analytical methods. Relative volume of nonmetallic inclusions were determine by inspecting metallographic specimens with the use of a Quantimet video inspection microscope under 400x magnification. It was determined for a larger boundary value of $2 \mu \mathrm{m}$. The percentage of sulfur-based inclusions was below the value of error in determinations of the percentage of oxygen-based inclusions, therefore, sulfur-based inclusions were excluded from further analyses. The main focus of the analysis was on oxygen-based inclusions.

The analyzed sections had a cylindrical shape and a diameter of $10 \mathrm{~mm}$. Their main axes were oriented in the direction of processing. The sections were thermally processed to determine differences in their structural characteristics. They were hardened for 30 minutes from the austenitizing temperature of $880{ }^{\circ} \mathrm{C}$ and quenched in water. The analyzed samples were tempered for 120 minutes at a temperature of 200, 300, 400, 500 or $600{ }^{\circ} \mathrm{C}$ and cooled in air.

Fatigue strength was determined for all heats. Heat treatment was applied to evaluate the effect of hardening on the fatigue properties of the analyzed material, subject to the volume of fine non-metallic inclusions. Heat treatments were selected to produce heats with different microstructure of steel, from hard microstructure of tempered martensite, through sorbitol to the ductile microstructure obtained by spheroidization. The application of various heat treatment parameters led to the formation of different microstructures responsible for steel hardness values in the following range from 249 to $438 \mathrm{HV}[19,20]$.

The test was performed on a rotary bending fatigue testing machine at $6000 \mathrm{rpm}$. The endurance (fatigue) limit was set at $10^{7}$ cycles. The level of fatigue-inducing load was adapted to the strength properties of steel. Maximum load was set for steel tempered at a temperature of $200^{\circ} \mathrm{C}-650 \mathrm{MPa}$, from $300{ }^{\circ} \mathrm{C}$ to $500{ }^{\circ} \mathrm{C}-$ $600 \mathrm{MPa}$ and for $600{ }^{\circ} \mathrm{C}-540 \mathrm{MPa}$.

The arithmetic average size proportions and distances between the impurities of structural steel a were calculated with the use of the below formula (1):

$\alpha=\frac{d}{\lambda}$ 
where:

$\mathrm{d}$ - average diameter of impurity $(\mu \mathrm{m})$

$\lambda$ - arithmetic average distance between impurities $(\mu \mathrm{m})$

The arithmetic average distances between impurities for each of the heats $\lambda$ were calculated with the use of the below formula (2):

$\lambda=\frac{2}{3} d\left(\frac{1}{V}-1\right)$

where:

$\mathrm{d}$ - average diameter of impurity $(\mu \mathrm{m})$

$\mathrm{V}$ - relative volume of submicroscopic impurities (\%)

Coefficient $k$ is the quotient of fatigue strength zg divided by Vickers hardness HV (3).

$k=\frac{z g}{H V}$

where:

$\mathrm{zg}$ - fatigue strength (MPa)

HV - Vickers hardness (HV)

The presence of statistically significant correlations was verified by Student's t-test on $\alpha=0.05$.

\section{RESULTS AND DISCUSSION}

The average real chemical composition of the tested steel is presented in Table 1.

Table 1 Real average chemical composition of the tested steel [wt. \%]

\begin{tabular}{|c|c|c|c|c|c|c|c|c|c|}
\hline $\mathbf{C}$ & $\mathbf{M n}$ & $\mathbf{S i}$ & $\mathbf{P}$ & $\mathbf{S}$ & $\mathbf{C r}$ & $\mathbf{N i}$ & $\mathbf{M o}$ & $\mathbf{C u}$ & $\mathbf{B}$ \\
\hline 0.23 & 1.21 & 0.28 & 0.02 & 0.01 & 0.47 & 0.46 & 0.23 & 0.15 & 0.003 \\
\hline
\end{tabular}

Fatigue strength coefficient $\mathrm{k}$ of hardened steel tempered at $200,300,400,500$ and $600{ }^{\circ} \mathrm{C}$ subject the quotient of the diameter of impurities and the spacing between impurities $\alpha$ are presented respectively in Figures $1-5$. The regression equation and the value of the correlation coefficient $r$ are shown respectively in (4)-(8).

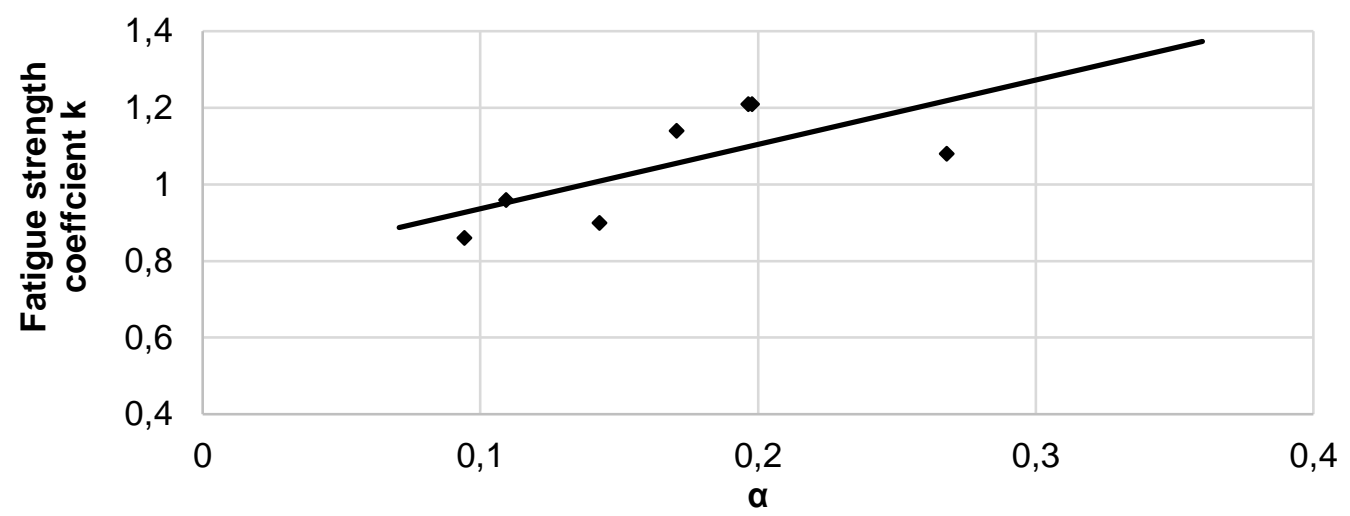

Figure 1 Fatigue strength coefficient $\mathrm{k}$ of hardened steel tempered at $200^{\circ} \mathrm{C}$ subject the quotient of the diameter of impurities and the spacing between impurities $\alpha$ 


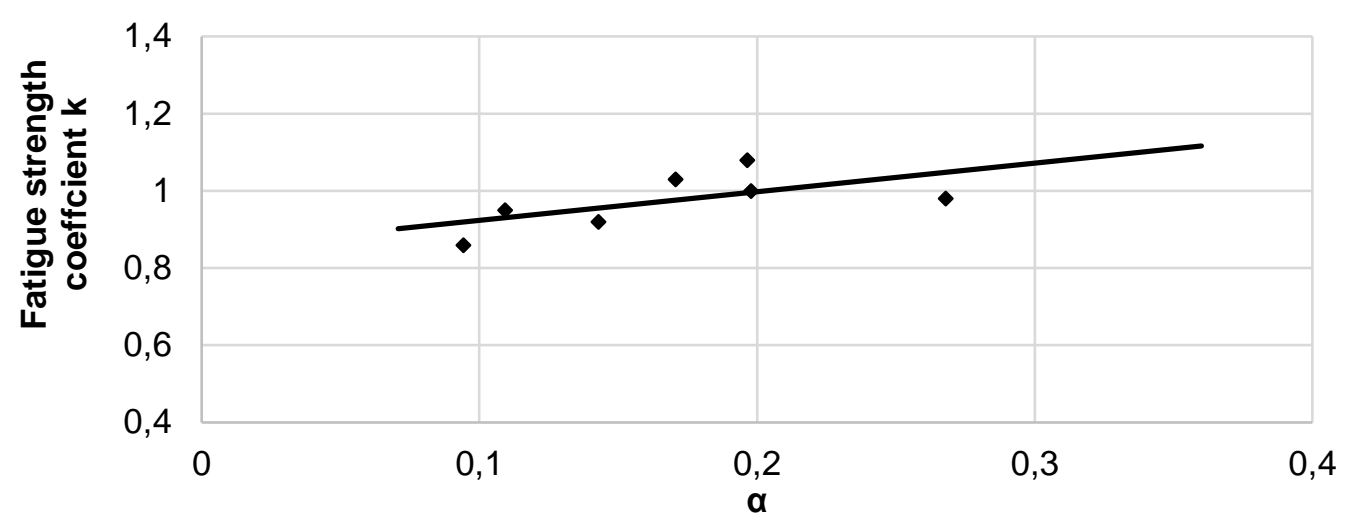

Figure 2 Fatigue strength coefficient $\mathrm{k}$ of hardened steel tempered at $300^{\circ} \mathrm{C}$ subject the quotient of the diameter of impurities and the spacing between impurities $\alpha$

$\mathrm{k}(300)=0.741 \cdot \alpha+0.8495$ and $r=0.6073$

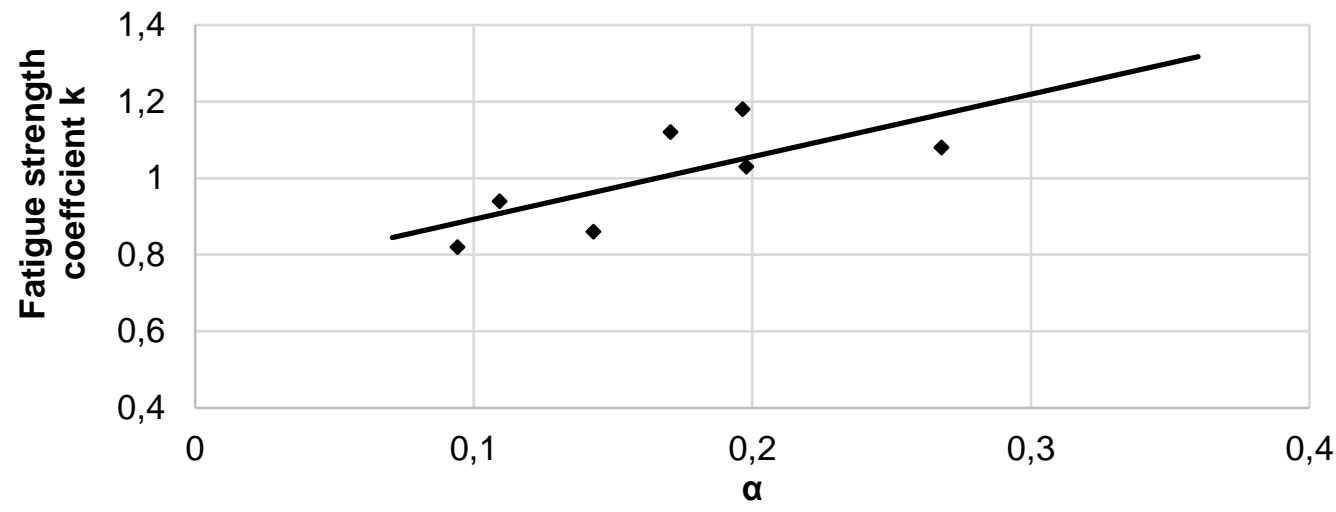

Figure 3 Fatigue strength coefficient $\mathrm{k}$ of hardened steel tempered at $400^{\circ} \mathrm{C}$ subject the quotient of the diameter of impurities and the spacing between impurities $\alpha$

$k(400)=1.6326 \cdot \alpha+0.7293$ and $r=0.7183$

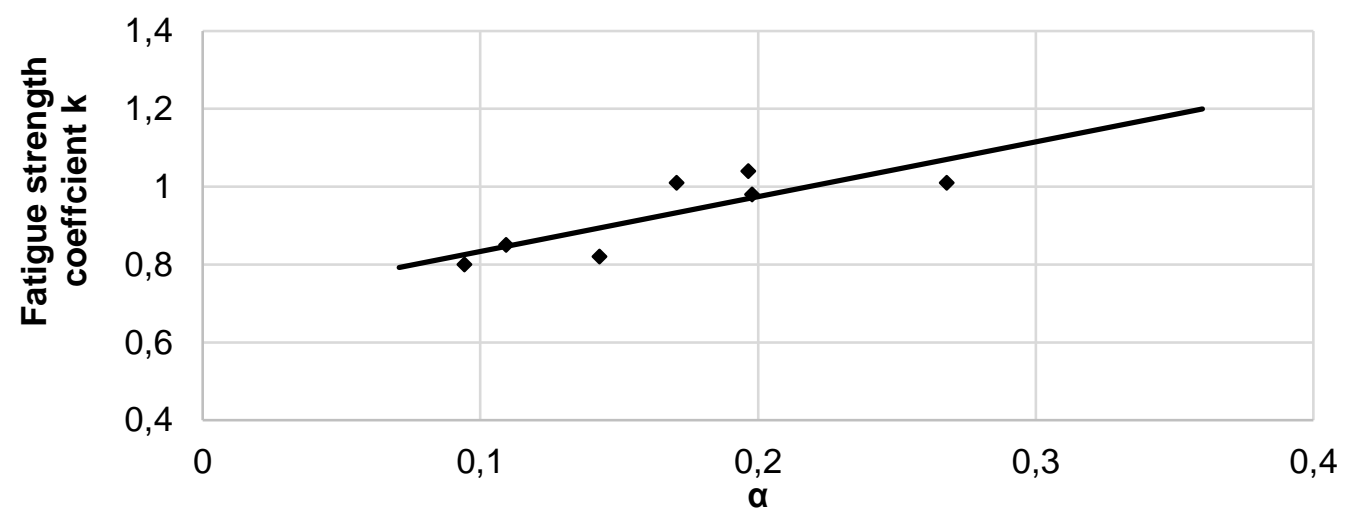

Figure 4 Fatigue strength coefficient $\mathrm{k}$ of hardened steel tempered at $500^{\circ} \mathrm{C}$ subject the quotient of the diameter of impurities and the spacing between impurities $\alpha$ 


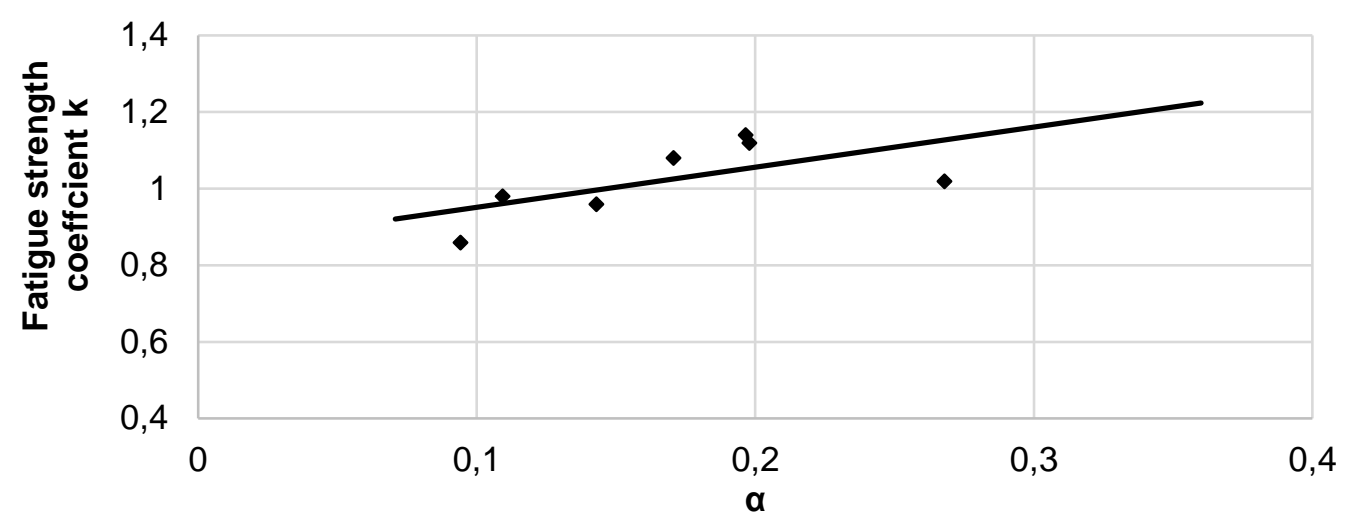

Figure 5 Fatigue strength coefficient $\mathrm{k}$ of hardened steel tempered at $600{ }^{\circ} \mathrm{C}$ subject the quotient of the diameter of impurities and the spacing between impurities $\alpha$

$k(600)=1.0473 \cdot \alpha+0.8187$ and $r=0.6294$

Diameter of impurities divided by spacing between impurities $(\alpha)$ of structural steel for all tempering temperatures, takes values from 0.1 to 0.2 , except for one point for $\alpha=0.27$. This point significantly reduces the coefficient of determination of equations (3) - (7). The presence of a coefficient in such a narrow range can confirm the balanced distribution and size of non-metallic inclusions. This observation is confirmed by the results presented in [21,22].

Fatigue strength coefficient $\mathrm{k}$ of hardened medium carbon structural steel tempered at different temperatures is in the range of 0.8 to 1.2. Its values above unity were recorded for $\alpha>0.15$. Its largest spread was noted for the tempering temperature of $400^{\circ} \mathrm{C}$ (Figure 3), and not the lowest for $500^{\circ} \mathrm{C}$ (Figure 4).

As the diameter of impurities divided by spacing between impurities $(\alpha)$ increased, $k$ increased for all tempering temperatures (Figures 1-5). This may confirm that large inclusions and short distances between them reduce the fatigue strength of steel. The largest reduction in fatigue strength of steel was recorded for the tempering temperature of $500{ }^{\circ} \mathrm{C}$ (Figure 4), for which the coefficient $\mathrm{k}$ takes values from 0.8 to 1.04 .

\section{CONCLUSION}

This study demonstrated correlations between the diameter of non-metallic inclusions divided by spacing between impurities and the bending fatigue coefficient for different range of tempering temperature.

The results of the study indicate that fatigue strength, represented by fatigue strength during rotary bending, is correlated with the size proportions and distances between the impurities measuring higher up $2 \mu \mathrm{m}$.

The coefficient $k$ allows for estimating fatigue strength in relation to diameter of impurities and the spacing between impurities.

The use of the a parameter allows the combination of two important parameters characterizing the impurities in steel, namely the diameter of impurities and the spacing between impurities.

Along with the increase in a parameter, an increase in coefficient $\mathrm{k}$ was noted for all tempering temperatures. This confirms that for small inclusions and large distances between them, the fatigue strength of steel is not reduced.

\section{REFERENCES}

[1] KIESSLING, R. Non-metallic inclusions in steel. The Institute of Materials, London, UK 1978. 
[2] CORNELIUS, T., BIRGER, K. and NILS-GUNNAR, I. Fatigue anisotropy in cross-rolled, hardened medium carbon steel resulting from MnS inclusions. Metallurgical and materials transactions. 2006. vol. 37A, pp. 29953007.

[3] MURAKAMI, Y. Metal fatigue: Effects of small defects and inclusions. Amsterdam: Elsevier, 2002.

[4] MOUSAVI, S.M. and PAAVOLA, J. Analysis of a cracked concrete containing an inclusion within homogeneously imperfect interface. Mechanics Research Communications. 2015. vol. 63, pp. 1-5.

[5] ANDERSON, C.W. and COLES, S.G. The largest inclusions in a piece of steel. Extremes. 2002. vol. 5, pp. 237-252.

[6] KOCAŃDA, S. and SZALA. J. Basis of fatigue calculation. Warszawa: PWN, 1985, p. 288.

[7] ULEWICZ, R., SZATANIAK, P. and NOVY, F. Fatigue properties of wear resistant martensitic steel. In METAL 2014: 23rd Int. Conf. on Metallurgy and Materials. Ostrava, TANGER, 2014, pp. 784-789.

[8] SZATANIAK, P., NOVY, F. and ULEWICZ, R. HSLA steels - comparison of cutting techniques. In METAL 2014: 23rd Int. Conf. Metallurgy and Materials. Ostrava: TANGER, 2014, pp. 778-783.

[9] BORKOWSKI, S., ULEWICZ, R., SELEJDAK, J., KONSTANCIAK, M. and KLIMECKA-TATAR, D. The use of 3x3 matrix to evaluation of ribbed wire manufacturing technology. In METAL 2012: 21st Int. Conf. on Metallurgy and Materials. Ostrava: TANGER, 2012, pp. 1722-1728.

[10] DUDEK, A. and KOLAN, C. Assessments of Shrinkage Degree in Bioceramic Sinters HA+ZrO(2). Solid State Phenomena. 2009, vol. 165, pp. 25-30.

[11] MARUSZCZYK, A., DUDEK, A. and SZALA, M. Research into morphology and properties of TiO2-NiAl atmospheric plasma sprayed coating. Adv. Sci. Technol. Res. J. 2017, vol. 11, pp. 204-210.

[12] GADEK-MOSZCZAK, A., RADEK, N., WRONSKI, S. and TARASIUK, J. Application the 3D Image Analysis Techniques for Assessment the Quality of Material Surface Layer Before and After Laser Treatment. Advanced Materials Research-Switz. 2014, vol. 874, pp.133-138.

[13] GADEK-MOSZCZAK, A., PIETASZEK, J., JASIEWICZ, B., SIKORSKA, S. and WOJNAR, L. The Bootstrap Approach to the Comparison of Two Methods Applied to the Evaluation of the Growth Index in the Analysis of the Digital X-ray Image of a Bone Regenerate. New Trends in Comp. Collective Intell. 2015, vol. 572, pp.127-136.

[14] WOJNAR, L., GADEK-MOSZCZAK, A. and PIETRASZEK, J. On the role of histomorphometric (stereological) microstructure parameters in the prediction of vertebrae compression strength. Image Analysis and Stereology. 2019, vol. 38, pp.63-73.

[15] PACANA, A., BEDNAROVA, L., LIBERKO, I. and WOZNY, A. Effect of selected production factors of the stretch film on its extensibility. Przemys/ Chemiczny. 2014, vol. 93, pp. 1139-1140.

[16] PACANA, A., RADON-CHOLEWA, A., PACANA, J. and WOZNY, A. The study of stickiness of packaging film by Shainin method. Przemysl Chemiczny. 2015, vol. 94, pp. 1334-1336.

[17] PACANA, A., PASTERNAK-MALICKA, M., ZAWADA. M. and RADON-CHOLEWA, A. Decision support in the production of packaging films by cost-quality analysis. Przemysl Chemiczny. 2016, vol. 95, pp. 1042-1044.

[18] PIETRASZEK, J. Fuzzy Regression Compared to Classical Experimental Design in the Case of Flywheel Assembly. In RUTKOWSKI L., KORYTKOWSKI M., SCHERER R., TADEUSIEWICZ R., ZADEH L.A., ZURADA J.M. (eds) Artificial Intelligence and Soft Computing ICAISC 2012. Lecture Notes in Computer Science, vol 7267. Berlin: Heidelberg: Springer, 2012, pp. 310-317.

[19] WACH, A. Impact of secondary metallurgy on some properties of structural steel used on machine parts. Olsztyn, 2010. Ph.D. thesis. University of Warmia and Mazury in Olsztyn.

[20] LIPINSKI, T. and WACH, A. The Effect of Fine Non-Metallic Inclusions on The Fatigue Strength of Structural Steel. Arch. Metall. Mater. 2015. vol. 60, pp. 65-69.

[21] LIPINSKI, T. and WACH, A. Non-metallic inclusions structure dimension in high quality steel with medium carbon contents. Archives of Foundry Engineering. 2009, vol. 9, pp. 75-78.

[22] LIPINSKI, T. and WACH, A. Dimensional structure of non-metallic inclusions in high-grade medium carbon steel melted in an electric furnace and subjected to desulfurization. Solid State Phenomena. 2015, vol. 223, pp. 46-53. 